\title{
LA DIGRESIÓN SOBRE LOS PECADOS MORTALES Y LA ESTRUCTURA DEL LIBRO DE BUEN AMOR
}

Aunque se ha reconocido que el Libro de buen amor tiene la forma de una seudoautobiografía amorosa, así como varias divisiones y subdivisiones băsicas, predomina aún la opinión de que la obra en su totalidad sólo alcanza cierta unidad artificial, debido a su afán de unir composiciones heterogéneas frecuentemente preexistentes. Un eminente crítico ha llegado incluso a opinar que para seguir la unidad (o consecuencia) de la obra es preferible desatender todas las repeticiones y digresiones, es decir, todos los elementos no progresivos ${ }^{1}$.

Debemos recordar, sin embargo, que la composición poética en los autores medievales era distinta de la ordenación lineal que prevalece hoy en día, con su principio y fin nítidamente delineados y con una clara noción de la trama. Los autores medievales, particularmente los de obras extensas, tendían a interesarse en una secuencia muy diferente. Algunos de estos textos, que a primera vista nos podrían parecer colecciones desordenadas, eran en realidad obras unificadas, a menudo con el tema unificador, que

${ }^{1}$ Según G. Sobejano, es "mejor no atender a los preliminares ni a los ápendices, como tampoco a repeticiones, digresiones o incisos[...] se debe desatender los elementos no progresivos, donde la unidad puede aparecer menos evidente", "Consecuencia y diversidad en el Libro de buen amor", en CAH(1), p. 7. Aunque el presente estudio forma parte de una obra más extensa, cuya intención es estudiar los eslabones unificadores del $L B A$ a través de sus elementos lineales y digresivos, no intentaremos hablar aquí de la estructura entera de la obra. Para un visión general de las opiniones más importantes sobre el tema, véase C. Nepaulsingh, "The structure of the Libro de buen amor", $N$, 61 (1977), 58-73. Debe tenerse en cuenta que los estudios sobre la estructura han tendido a desestimar gran parte de los elementos digresivos, aunque sin exponer su intención tan explícitamente como lo hace Sobejano. 
(formulado explícita o implícitamente en el prólogo) determinaba las normas para la selección y adaptación de los materiales heredados. La originalidad poética consistía precisamente en la hábil combinación de elementos conocidos y en lograr una unidad coherente a partir de un material amorfo heredado. No interesaba tanto explicar o desarrollar la acción hasta un cierto clímax como enlazar un grupo de episodios independientes, con el propósito de establecer, o por lo menos sugerir, conexiones entre temas no relacionados previamente.

Como ha mostrado E. Faral, la elaboración de la técnica de la amplificatio es precisamente lo que diferencia a los teóricos y escritores de los siglos XII y XIII de sus modelos clásicos ${ }^{2}$. En la reinterpretación medieval del término, la amplificación es un despliegue de temas interrelacionados. De ahí la insistencia en una forma particularmente elegante de amplificación, la digressio, doctrina que contradice la unidad monocéntrica, más común, y justifica la expansión y la diversidad.

Faral, quien afirmaba que los escritores del medioevo estaban poco interesados en la composición, da una visión bastante negativa de la amplificación, equiparándola con la mera dilatación. Sin embargo, según ha mostrado elocuentemente Gunn en su estudio de la estructura del Roman de la Rose, las aparentes digresiones de la línea narrativa principal pueden ser amplificaciones deliberadas del tema central del autor ${ }^{3}$.

${ }^{2}$ Edmond Faral, Les arts poétiques du xii et du xiii ${ }^{e}$ siècle, 1924; reed., Honoré Champion, Paris, 1962.

${ }^{3}$ Véase Alan M. F. GunN, The mirror of love, a reinterpretation of the Romance of the Rose, Texas Tech Press, Lubbock, 1952, pp. 67-94. También son interesantes los comentarios de A. DeYermond sobre la estructura aparentemente amorfa del Libro de Alexandre, igualmente aplicables al $L B A$ : “las varias fuentes se hallan combinadas con sumo cuidado, generalmente con excelentes resultados, dentro de una estructura compleja. Las que a nivel superficial se nos presentan como meras digresiones[...] se han considerado como irrelevantes y como elementos débiles desde el punto de vista estructural pero el Libro de Alexandre, con todo, se halla dotado de una unidad mediante el procedimiento cuidadoso de entretejer los temas y los episodios[...]. Las digresiones aparentes sirven, pues, para realzar los temas de mayor avergadura"' (La Edad Media, t. 1 de la Historia de la literatura española, Ariel, Barcelona, 1971). Véanse también JUDson Boyce Allen y Theresa Anne Moritz, $A$ distinction of stories. The Medieval unity of Chaucer's fair chain of narratives for Canterbury, Ohio State University Press, Columbus, 1881; y Judson Boyce Allen, The ethical poetic of the Later Middle Ages. A decorum of convenient distinction, University of Toronto Press, Toronto, 1982, para una exposición detallada de la forma tractandi 'forma del tratado', en el que se especifican diversos modos de poesía, y su complemento, forma tractatus 'forma del tratamiento' que especificaba el orden literal de las partes 
Si analizamos el $L B A$ desde esta perspectiva, lo que tenemos que examinar es la destreza de Juan Ruiz en no perder de vista su tema central, incluso en sus digresiones más extensas, y su habilidad para ajustar los materiales heredados al contexto de su complejo esquema. Para ejemplificar tal maestría, mi propósito es estudiar la función estructural y temática de la digresión sobre los pecados mortales en la obra en su conjunto. Es ésta la digresión más extensa del libro, pues cubre casi una décima parte de la obra y está contenida dentro de un debate digresivo todavía más extenso, de casi cuatrocientas estrofas, entre el Poeta y Don Amor. . Casi la mitad del vituperio del poeta en este debate es una especie de sermón religioso, en el cual acusa a Amor de ser la causa de todos los pecados mortales.

Los pocos críticos que han abordado esta sección del $L B A$ han tendido a estudiarla en sus relaciones extratextuales, para determinar, por ejemplo, la tradición teológica que seguía Juan Ruiz en la ordenación de los pecados y el motivo por el cual incluye ocho pecados en lugar de siete. Estos críticos, en general, han pasado por alto la estructura del episodio en sí o han expresado al respecto juicios bastante duros. Así, Lecoy la calificó de "trivial", alegando que describía un "cuadro horrible" de los males de los pecados, pero que su composición no implicaba casi ningún esfuerzo ${ }^{5}$.

del texto; véase también J. BURKe, "A new critical approach to the interpretation of Medieval Spanish literature", LCo, 11 (1983), 273-279.

${ }^{4}$ De las 1,709 estrofas de la obra, las coplas 181-575 están dedicadas a la "Pelea con Don Amor". De éstas, las coplas 207-387, el diez por ciento, se relacionan directamente con los pecados mortales. Para dar una mejor perspectiva de la extensión y consecuentemente de la importancia de esta digresión, tan sólo necesitamos compararla con el tratamiento del mismo tema en el Libro de Alexandre, a veces considerado como su fuente, donde los pecados comprenden las coplas 2345-2411, o sesentaiséis estrofas, que constituyen aproximadamente el dos y medio por ciento del total. De hechọ, la pelea entre el Arcipreste y Don Amor es considerablemente más extensa que la famosa digresión sobre Troya en el Alexandre (el dieciséis por ciento de la obra); quizás no da la impresión de ser tan extensa debido a que es menos digresiva en apariencia. Sobre las divisiones del Alexandre, véanse IAN Michael, The treatment of classical material in the "Libro de Alexandre", University Press, Manchester, 1980, y "The description of hell in the Spanish Libro de Alexandre", en Medieval miscellany presented to Eugène vinaver, University Press, Manchester, 1965, pp. 220-229.

${ }^{5}$ Felix Lecoy dijo también que "la strophe 520 brise fâcheusement le fil de la narration pour souligner una généalogie de péchés assez hors de propos" (Recherches sur le "Libro de buen amor", with supplementary material by A. Deyermond, Gregg International, Westmead, 1977, p. 178). Véase asimismo 
Debe tenerse en cuenta que los pecados aparecen específicamente en otras tres secciones del libro: en el cuento sobre el ermitaño borracho (528-43); en la sección sobre la penitencia impuesta por un fraile a Don Carnal, hipócritamente arrepentido (1162-72); y, finalmente, en el sermón sobre "las armas del cristiano" en contra de la Trinidad Infernal, el Diablo, la Muerte, y el Mundo (1579-1605). Los pecados reaparecen asimismo en

JOAN COROMINAS, quien parece sentir aversión por esta sección: "fastidioso sermón contra Don Amor... parece ser obra de un hombre maduro y sin ilusiones que trata de obtener un efecto práctico en la vida... Todo esto, en interminables y monótonas series heptasilábicas"' (JuAN RuIZ, Libro de buen amor, ed. crítica de J. Corominas, Gredos, Madrid, 1967, p. 55). AnTHony ZahA. REAS, en su excelente The art of Juan Ruiz, Archpriest of Hita (Estudios de Literatura Española, Madrid, 1965), opina que la invectiva, larga en exceso, y en partes tediosa, representa quizás el mayor enigma y obstáculo para la consideración de las dotes artísticas de Juan Ruiz. Véanse opiniones similares expresadas por G. B. GybBon-Monypenny, "Autobiography in the Libro de buen amor, in the light of some literary comparisons", BHS, 34 (1957), 63-78.

Otros estudios que han tratado esta sección directamente y con cierto detalle son: J. A. CHAPMAN, "A suggested interpretation of stanzas 528 to 549 a of the Libro de buen amor", RF, 73 (1961), 29-39; R. RiCARD, "Les péchés capitaux dans le Libro de buen amor", $L R, 20$ (1966), 5-37; R. M. WALKER, "«Con miedo de la muerte la miel non es sabrosan: Love, sin and death in the Libro de buen amor", en $L B A S$, pp. 231-252; Allicia C. de Ferraresi, De amor y poesía en la España medieval: prólogo a Juan Ruiz, El Colegio de México, México, 1976; Luis BELTRÁn, Razones de buen amor. Oposiciones y convergencias en el libro del Arcipreste de Hita, Fundación March-Castalia, Madrid, 1977; Eliezer OYoLA, Los pecados capitales en la literatura medieval española, Puvill, Barcelona, 1979; J. K. WALSH, "Juan Ruiz and the mester de clerecia: Lost context and lost parody in the Libro de buen amor", $R P h, 33$ (1979-80), 62-86. Este último autor es el único que parece reconocer un intento paródico en el episodio (pp. 81-82).

En un sentido más general, aparte de la obra maestra de MorTon BloOMFIELD (The seven deadly sins. An introduction to the history of a religious concept, Michigan State University Press, East Lansing, 1952; reed., 1967), son también relevantes: R. TuvE, "Notes on the virtues and vices", JWC, 26 (1963), 264303; S. WENZEL, "Dante's rationale for the seven deadly sins", $M L R, 60$ (1965), 529-533, donde se sugiere que el concepto de Dante expresado por Virgilio en el "Purgatorio", de que todos los vicios son causados por el amor inordinatus, está basado en la Summa de vitiis et virtutibus de Peraldus; del mismo autor, "The seven deadly sins. Some problems of research", $S p, 43$ (1968), 1-22, y The sin of sloth, "Acedia" in Medieval thought and literature of love, University of North Carolina Press, Chapel Hill, 1967. Véase también Adolf KatZENELLENBOGEN, Allegories of the virtues and vices in Medieval art, from earty Christian times to the thirteenth century, The Warburg Institute, London, 1939, quien discute la tradición iconográfica de las alegorías de las virtudes y los vicios. Para la terminología romanceada de los vicios y virtudes en castellano, véase M. Morreale, "Los catálogos de virtudes y vicios en lás Biblias romanccadas de la Edad Media", NRFH, 12 (1958), 149-159. 
otras partes del libro, por ejemplo, en la descripción de la avaricia de los familiares de un hombre recién fallecido, quienes, en lugar de rezar por su alma, sólo se preocupan por obtener sus bienes (1539-41). No me detendré en esta ocasión en los paralelismos de estas secciones y me limitaré a mencionar tan sólo unos cuantos puntos importantes: Juan Ruiz empleó más tiempo en contar los vicios que en combatirlos; dedica un total de diez estrofas a la penitencia (que además era una penitencia hipócrita), dieciséis a las "armas del cristiano" y ciento setenta a los pecados.

La doctrina y la terminología empleadas para catalogar los pecados fueron durante mucho tiempo muy imprecisas y Juan Ruiz no sigue exactamente en su ordenación ninguna tradición establecida. Su serie de ocho en lugar de siete pecados no está encabezada por la soberbia, conforme a la tradición más común, sino por la codicia, que será considerada el pecado esencial. Más que seguir la estructura por concatenación, en la cual todos los pecados están eslabonados entre sí, el patrón que sigue Juan Ruiz, dentro de la tradición de San Pablo, es el del arbor vitiorum, análogo a la conocidísima Summa de vitiis et virtutibus de William Peraldus del segundo cuarto del siglo XIII, donde todos los vicios surgen del amor inordinatus ${ }^{6}$. El orden de los pecados es el siguiente: 1. codicia, 2. soberbia, 3. avaricia, 4. lujuria, 5. envidia, 6. gula, 7. ira y vanagloria, 8. acidia e hipocresía. Esta ordenación ocasiona varias confusiones. Al considerar la codicia como raíz de todos los otros pecados, Juan Ruiz sintió al parecer la necesidad de poner en lista siete pecados que emanaran de ésta y, así, coloca en tercer lugar la avaricia, que es en realidad una duplicación de la codicia. El Alexandre, por ejemplo, considera la codicia y la avaricia conjuntamente, como "compañeras" y "serores", pero las distingue un poco diciendo que lo que la codicia podría recoger, la avaricia lo soterraría 7 . Juan Ruiz incluye la vanagloria y la ira en

${ }^{6}$ Sobre Peraldus, véase S. Wenzel, art. cit.; a Peraldus también se ha propuesto como la fuente o el análogo del tratamiento de los pecados en el "Parson's tale" de los Canterbury tales (véase G. DemPSTER, "The Parson's tale", en Sources and analogues of Chaucer's "Canterbury tales", eds. W. F. Bryan and G. Dempter, Humanities Press, New York, 1941; reed., 1958, pp. 728-760.

${ }^{7}$ Cf. Alex. $2347 \mathrm{ab}$ quanto dona Cobdiçia podié ir aportando/iva Avariçia so tierra condesando (Dana Nelson, ed., Libro de Alexandre, Gredos, Madrid, 1979, p. 197). Esta definición parece ser común; compárese, por ejemplo, el Manuel des Pechiez de William of Wadington: 4460 Que coueitise est en purchaçant/E avarice en retenant (ed. F. Furnivall, London, 1901). RichaRd (art. cit.) apunta que la distinción entre cupiditas y avaritia no está clara en Santo Tomás, pero que el primero es el término más general. Véase 1539-41, donde Juan Ruiz habla 
el séptimo pecado, cuando la primera es normalmente una subcategoría de la soberbia y la segunda una variante de la envidia ${ }^{8}$. Si consideramos aparte la codicia y desestimamos la vanagloria y la hipocresía, emparejadas con otros pecados, los restantes siguen la ordenación mnemotécnica saligia, utilizada en las escuelas. La ordenación, pues, no tiene que tener implicaciones conceptuales especiales, aunque Ferraresi $^{9}$ hace la interesante observación de que Juan Ruiz escogió deliberadamente la codicia como el pecado raíz, al igual que el autor del Alexandre se sirvió de la tradición que colocaba en primer lugar a la soberbia por ser precisamente la soberbia de Alexandre, comparable a la de Lucifer, la causa de su condena final (Alex., 2327).

La presentación de cada pecado se divide en tres partes: 1. introducción y definición del pecado 2. uno o varios exempla en forma de fábulas ${ }^{10}$ o cuentos ilustrativos 3 . una o más moralejas que se desprenden de lo anterior. Observaremos que en cada uno de los pecados Juan Ruiz hará uso de variaciones, al menos en una de estas tres divisiones, para enlazar los materiales heredados con su molde temático ${ }^{11}$.

Antes de examinar el texto en cuestión, debemos recordar dos

de los parientes de un hombre muerto que están ansiosos por soterrarle con el fin de conseguir sus riquezas; podría haber un juego consciente con soterrar "enterrar las riquezas mal adquiridas".

${ }^{8}$ Hay un breve estudio de la asociación de la vanagloria con la ira en MAría Rosa Lida De Malkiel, ed., Selecciones del "Libro de buen amor"' y estudios críticos, Eudeba, Buenos Aires, 1973, p. 186.

${ }^{9}$ Op. cit., p. 201.

${ }^{10} \mathrm{~S}$. J. KAHRL ("Allegory in practice: A study of narrative styles in Medieval exempla", $M P h, 63,1965-66,105-110$ ) estudia narratio 'verdadera narrativa' e historia frente a fábula 'narrativa ficticia'. Para la distinción mucho más estricta de la narración como un "cuento de hombres y mujeres" y la fábula como un "cuento de animales", véase G. R. OwsT, Literature and pulpit in Medieval England, Cambridge University Press, Cambridge, 1933; 2nd ed., Basil \& Blackwell, Oxford, 1961, p. 152. Mientras la mayor parte de los exempla de Juan Ruiz tienen a animales por protagonistas, algunos tienen sujetos humanos. Véase también S. BATtaglia, "L'esempio medievale", $F R, 6$ (1959), 185-224; reed., La coscienza letteraria nel medioevo, Liguori, Napoli, 1965, pp. 447-485.

${ }^{11}$ Los eruditos se han centrado generalmente en el problema de catalogar los exempla y en averiguar su historia literaria, y apenas se han preocupado en estudiar cómo son adaptados a diferentes contextos. Para una visión general del uso medieval de los exempla, véase J. T. Welter, L'exemplum dans la littérature religieuse et didactique du moyen âge, E. H. Guitard, Paris, 1927; para un catálogo del $L B A$, véase I. MichaeL, "The function of the popular tale in the Libro de buen amor', en $L B A S$, pp. 177-218. 
pasajes muy conocidos. El primero aparece en la conclusión de la introducción en prosa que, como se ha demostrado de manera convincente, tiene la forma de un sermón paródico vernáculo y culto. Esta introducción sigue el modelo de las artes praedicandi ${ }^{12}$ y se desarrolla alrededor del thema o de la cita inicial (del Salmo XXXI) que comienza "Intellectum tibi dabo..."': "Te daré entendimiento y te enseñaré el camino en que has de andar"'. El prólogo anticipa la estructura total de la obra, basada en una yuxtaposición paródica de contrarios ambiguos. Concluye así:

E compuse este nuevo libro en que son escritas algunas maneras e maestrías e sotilezas engañosas del loco amor del mundo, que usan algunos para pecar. Las quales, leyéndolas e oyéndolas omne o mujer de buen entendimiento, que se quiera salvar, descogerá e obrarlo ha... Empero, porque es umanal cosa el pecar, si algunos, lo que non les consejo, quisieren usar del loco amor, aquí fallarán algunas maneras para ello ${ }^{13}$.

12 Sobre la estructura del prólogo como sermón véase J. A. Chapman, “Juan Ruiz's learned sermon", en $L B A S$, pp. 29-51; C. NePaulsingh, "The rhetorical structure of the prologues to the Libro de buen amor and the Celestina", BHS, 51 (1974), 325-334; sobre el carácter paródico del prólogo, véase A. Deyermond, "Some aspects of parody in the Libro de buen amor", en LBAS, pp. 56-57. Sobre el sermón en la literatura castellana medieval, véase también A. Deyermond, "The sermon and its uses in Medieval Castilian literature", LCo, 8 (1979-80), 127-145. Para una discusión sobre el sermón como forma literaria (aunque con énfasis en períodos posteriores), véase PETER BAYLEY, French pulpit oratory: 1598-1650, Cambridge University Press, New York, 1980, y también G. R. Owst, op. cit. Sobre la liturgia paródica de la Cuaresma, véase H. Fluck, "Der Risus Paschalis: ein Beiträg zur Religiosen Volkskunde", 'Archiv für Religionswissenschaft, 31 (1934), 188-212. Sin embargo, J. BURKE ("The Libro de buen amor and the Medieval meditative sermon tradition", LCo, $9,1980-81,122-217)$ expresa serias dudas sobre el carácter paródico del sermón introductorio. Lecoy fue el primer erudito en referirse al prólogo del $L B A$ con el nombre medieval del género, sermon joyeux, el cual es definido por The Oxford companion to French literature (eds. P. Harvey and J. E. Heseltine, Clarendon Press, Oxford, 1959) como "un sermón burlesco, predicado al principio en las iglesias medievales, especialmente en Francia, durante los carnavales en relación con la Fiesta de los Inocentes... posteriormente fue expulsado de la iglesia y se secularizó... Los elementos cómicos se basan especialmente en el contraste entre los pasajes piadosos de las Escrituras o de la liturgia y las escabrosidades entremezcladas (traducción nuestra de 55)".

${ }^{13}$ Esta cita y todas las posteriores del texto del Libro de buen amor son de la edición de Corominas con los signos diacríticos eliminados. Debería tenerse en cuenta, sin embargo, como apunta FaulHaber en su reseña del libro de Alicia C. DE Ferraresi (RPh , 34, 1981, 240-246), que la edición de Corominas adolece de ciertas idiosincrasias y que nuestro conocimiento del texto debe seguir siendo considerado, hasta cierto punto, provisional. 
De esta manera, el intellectum 'entendimiento' que se debe alcanzar puede entenderse como una guía para el amor de Dios y la salvación, o como un manual de seducción.

De una segunda sección introductoria, debemos recordar los verbos siguientes sobre la natura del hombre, una subversión de los preceptos aristotélicos ${ }^{14}$ :

73b-d omne, aves, animalias, toda bestia de cueva, quieren segund natura compaña siempre nueva, e quánto más el omne que a toda cosa s'mueva;

$74 a-d$ digo muy más del omne que toda crïatura: todas a tiempo cierto se juntan, con natura;

$74 \mathrm{a}-\mathrm{c}$ todas a tiempo cierto se juntan, con natura; el omne del mal seso, tod'ora sin mesura, cada que puede quier fazer esta locura.

Centrándonos ahora en nuestro texto (estrofa 217), nos encontramos con que el poeta, que afirma estar sobrio pero sañudo, se vuelve airadamente hacia Amor y lo acusa de traer siempre consigo los pecados mortales ${ }^{15}$. Añade, con San Pablo, que la codi-

${ }^{14}$ Como ha apuntado Zahareas (op. cit.) a pesar de que Juan Ruiz basa su división de mantenencia y juntamiento en los Animalia de Aristóteles, tan sólo se explaya en el segundo y lo concreta de diversas maneras, refiriéndose no genéricamente al hombre "género humano" sino a los hombres que desean la unión con mujeres "agradables"; todavía diferencia más al hombre de los otros animales por su apetito sexual y desordenado. Esta deformación intencional también proporcionará un tema recurrente a lo largo de la digresión sobre los pecados.

${ }^{15}$ En las "Armas del cristiano" Juan Ruiz alegará que la raíz de los pecados mortales reside en la Trinidad Infernal - Mundo, Demonio y Carne: $1604 \mathrm{ab}$ "todos los otros pecados mortales e veniales /déstos nacen, como ríos de las fuentes perenales". Cf. sobre la Trinidad Infernal, Donalo R. HoWARD, The three temptations. Medieval man in search of the world, Princeton University Press, Princeton, 1966, pp. 41-75. Esto no es una inconsistencia si consideramos que Don Amor es el Diablo. Véanse sobre este punto los argumentos de Nepaulsingh ("The structure of the Libro de buen amor", p. 63); y también FerRaresi (op. cit., p. 204). Otras pruebas pueden añadirse en apoyo de la tesis de Napaulsingh: después de contar el exemplum del garçon que quería casar con tres mujeres, el Arcipreste le lanza a Don Amor el insulto de que es: 197a-c “...padre del fuego, pariente de la llama;/ más arde e más se quema qualquier que te más ama;/ Amor, quien te más sigue, quémasle cuerpo e alma"; en donde están hábilmente combinados estos papeles duales: el del Amor que quema a los amantes con sus pasiones y el del Diablo que los quema eternamente en el infierno. Antes de comenzar la digresión sobre los pecados, el Arcipreste termina la parte introductoria de su invectiva diciendo que Amor está "urdiendo siempre, cobierto so mal paño" (216d), lo cual nos presenta la tí- 
cia es hija mayor de Amor y raíz de todos los demás pecados (I. Tim., VI. 16: radix enim omnium malorum est cupidtas). Sin embargo, mientras que para San Pablo, en la escala de valores cristianos, cupiditas, el polo opuesto o perversión de caritas, representa el desmedido deseo de los bienes temporales, para Juan Ruiz el término queda reducido a un sinónimo de la concupiscencia carnal. Aunque empieza acusando a los codiciosos de anhelar riquezas que no se han ganado, da a entender que éstos actúan así por una sola razón:

221a-c Cobdician los averes por complir las promesas muchos por tal cobdicia quë ellos non ganaron que con amor mandaron; lö ajeno furtaron.

Añade que Troya también fue destruida por un tipo específico de codicia, pues Paris raptó a Elena, a la cual "cobdiciaba servir'. En otras partes del libro ambos vocablos serán empleados a menudo con un sentido específicamente sexual ${ }^{16}$.

pica imagen del antiguo mito del Diablo disfrazado, tan sólo enseñando sus patas bajo el abrigo para revelar su verdadera identidad. Posteriormente, en la adaptación de Pamphilus, en una escena en la que Melón está a la puerta de Trotaconventos, que finge tratar airadamente de deshacerse de él, ella se refiere a él como el pecado carboniento (873b), glosado por Corominas como 'el demonio tiznado'. Unos cuantos versos más abajo, ella grita: “ ¡Don Melón, tiradvos dende!, ¿tróxovos ý ël diablo?" (875b); diablo que por supuesto, es con toda exactitud el que le envió si Amor es el diablo. Ambas referencias al diablo son amplificaciones hechas por Juan Ruiz de los versos latinos del original: Pamphilus est! Vultus nam bene mosco suos ( $\mathrm{Pa} 654)$; Quid vis? Aut cuius venisti nuncius ad nos? ( $\mathrm{Pa} 659)$. (Las correspondencias latinas están tomadas de la concordancia proporcionada por Dayle SeIDenspinner-Núñez en el apéndice de su libro The allegory of Good love: Parodie perspectivism in the "Libro de buen amor', University of California Press, Berkeley-Los Angeles, 1981.) Finalmente, el hecho de que es Don Amor quien encabeza la processio vitiorum, la procesión de los pecados, recuerda el papel idéntico de Satanás en muchas obras medievales. En el Mirour de l'omne de Gower, por ejemplo, el Diablo es responsable de siete pecados, encabezados por la Soberbia, mientras en la Faerie Queen de Spenser, Lucifera, la Soberbia, es arrastrada en un carro por los otros seis pecados, cuyo cochero es Satanás (véase J. B. FrIEDMAN, "A reading of Chaucer's Reeve's tale", Chaucer Review, 2, 1967, pp. 13-14). En la iconografía medieval la Bestia del Apocalipsis se representa como un Satanás de siete cabezas con siete pecados o cabezas. Algunos ejemplos llevan la inscripción "çeste beste senefie le deable" (véase R. Tuve, art. cit., ilustraciones 21, 22, 24).

${ }^{16}$ Sobre el significado de cobdiciar compárense la historia del ermitaño, el cual "cobdició fer fornicio" (539d), el cuento de los dos hombres perezosos, que "amos por una dueña estavan deseosos" (457c), y Doña Endrina confesando a Trotaconventos: "Lo que tú me demandas yö aquello cobdicio" 
Juan Ruiz no trata aquí, en el pecado correspondiente, la codicia en su sentido más amplio, pero sí lo hace en el monólogo de Don Amor sobre los efectos negativos del dinero (490-512), en donde queda desenmascarada la codicia y la consecuente hipocresía de todas las clases sociales, muy especialmente la de los clérigos. Más adelante, en uno de los episodios de las serranas, la codicia se asocia específicamente con la concupiscencia. En efecto, el débil Arcipreste es objeto de peticiones de regalos y dinero anticipado a cambio de los favores sexuales prometidos, lo que queda más sucintamente expresado en 1040bc, "Do non ay moneda / non ay merchandía" (pero también en 961de, 964d pas$\mathrm{sim}$ ). El último exemplum incluido en la codicia no contiene implicaciones sexuales directas; es la conocida historia del perro que lleva un pedazo de carne en la boca y la deja caer en el agua al ver su reflejo. La fábula ilustra la simple avaricia en su sentido más estricto, mostrándonos que Juan Ruiz no logró separar totalmente la codicia y la avaricia en dos pecados distintos. Sin embargo, la moraleja del cuento, "por sombra mintrosa e por su cuidar vano / la carne que tenía perdiola el alano", se refiere a los que perdieron sus almas debido a la "engañosa cupiditas", que no es sino un falso reflejo del amor divino.

A la soberbia, el segundo de los pecados, se le acusa de hacer desaparecer el miedo en el hombre y, por lo tanto, permitirle cometer robos y despojar a los caminantes de sus joyas preciosas, merced a las cuales puede comprar regalos a su amante: “joyas para tu amiga de qué las comprarás: / robas por esto e furtas..." (230cd). Es decir, la soberbia apenas se distingue de la codicia, y a ambas se les acusa básicamente del mismo mal: suscitar a un hombre a robar para obtener favores sexuales. También se acusa a la soberbia de: "forçar muchas mujeres casadas ë esposas, / vír-

(844a). Véase también el probable significado erótico de servir en "siempre quise guardarlas e siempre las serví" (107b), "en este signo atal creo que yo nací" (153a) "en servir a las dueñas punar e non en ál" (154b), passim; K. WHINNOM ofrece ejemplos tanto en español como en provenzal de servir utilizado como un eufemismo para el acto sexual ("Hacia una interpretación y apreciación de las canciones del Cancionero general', Fill, 13, 1968-69, p. 375). Compárese también serve en inglés medieval, "ser el amante de una mujer", "satisfacer los deseos de uno", "montar a la hembra [un animal masculino]" (Oxford Universal Dictionary). Compárese asimismo la feroz sátira del Gil Pérez Conde sobre el amor idealizado, en la cual se lamenta de que no ha dejado un hijo a su dama para que ésta lo recuerde (véase F. R. HollidaY, "The frontiers of love and satire in the Galician-Portuguese Medieval lyric"', $B H S, 39,1962$, 34-40): "mi non e com unha morte ben / por que vos non ficou de mi filho, / por quanto vos servi..." 
genes e solteras, viudas e religiosas"' (231cd). En otras palabras, la soberbia incita a desear y violar a mujeres de toda clase y situación. En las dos secciones posteriores del libro en que reaparecen los pecados, la soberbia se identifica de nuevo con el sexo, obviamente de acuerdo con la creencia común de que la penitencia debería ser opuesta al pecado correspondiente. Así, parte de la penitencia de Don Carnal por este pecado será abstenerse de tener relaciones sexuales (o "la lucha"): "En el día del lunes, por tu sobervia mucha / ... / irás oír las oras, non provarás la lucha" (1164a,c). Y, en las "Armas del Cristiano", bajo el pecado de soberbia, el hombre será avisado de nuevo: "non robar cosas ajenas; non forçar mujer, nin nada"' (1589c).

El exemplum que sigue a continuación es la famosa fábula del caballo soberbio y elegante, que de camino a la batalla desdeña al pobre asno sobrecargado. Cuando el caballo vuelve exánime del campo de batalla, es al asno a quien le toca reírse burlonamente de él. Éste es un cuento utilizado normalmente para ilustrar la soberbia venida abajo, la vuelta de la fortuna o el tema del ubi sunt, pero Juan Ruiz logra relacionarlo también con la acusación anterior de la soberbia que lleva a la violación, explicando que el caballo valiente tenía la obligación de ir a la batalla porque su dueño había violado a una dama: "Iva lidiar en campo el cavallo faziente / porque forçó la dueña el su señor valiente" (237ab). Hacia el final del cuento el desafortunado caballo se identifica tan completamente con su libidinoso dueño que la moraleja dice: "escota ël sobervio el amor de la dueña" (241d), es decir, "el soberbio caballo pagó el precio de su pasión por la dama"17.

${ }^{17}$ También es pertinente la elección de la fábula sobre un caballo y un caballero para ilustrar la soberbia, puesto que la soberbia era representada a menudo en la iconografía gótica como un jinete cayéndose de su caballo (véanse D. W. Robertson, A preface to Chaucer, Princeton University Press, Princeton, 1962, p. 176 y BERYL Rowland, Animals with human faces, University of Tennessee Press, Knoxville, 1973, pp. 103-112). Compárese, análogamente, la Summa praedicanticum de John BROMYARD, donde la figura del caballo y el jinete representan a hombres malos "nacidos expresamente para la condenación por los pecados de su carne" (apud, J. B. FriedMan, art. cit., p. 10). En última instancia, gran parte de toda esta tradición vuelve a la Psychomachia de Prudencio, del siglo $\mathrm{v}$, en donde los pecados están personificados por mujeres montadas sobre animales y la soberbia, entre ellos, se representa montando un caballo indómito, finalmente vencido por la Mens Humilis.

Vale la pena recordar que RAYMOND WILLIS en su edición y traducción al inglés del $L B A$ ("Libro de buen amor", with introduction and English paraphrase, Princeton University Press, Princeton, 1972), no queriendo aceptar la lectura de $241 \mathrm{~d}$, añade entre paréntesis [his master's], para que el verso en inglés rece 
Morreale ${ }^{18}$ opina que "valiente", aplicado en la primera estrofa tanto al caballo como al caballero (237a,c), no sólo tiene su significado central de fuerza física, sino que connota también potencia sexual. Compárese con el cuento del hijo del molinero, “mancebo bien valiente"(189a) y "o moço más valiente" (1542c), que puede satisfacer las necesidades sexuales de una viuda muy joven ${ }^{19}$. Tal connotación parece que ha estado presente desde la época clásica ${ }^{20}$.

A lo largo de su obra, Juan Ruiz equipara al hombre movido por instintos sexuales con los animales inferiores, imagen que tiene antecedentes en Andrés el Capellán, que compara a los hombres con los perros y los asnos ${ }^{21}$. El caballo, representado a menudo como una entidad inseparable de su jinete y que simboliza los instintos sexuales básicos de éste, es un arquetipo muy extendido en la mitología y el folklore ${ }^{22}$.

"the prideful horse paid the price of [his master's] passion for the lady" (el caballo soberbio pagó el precio de la pasión de su dueño por la dama). Creo, sin embargo, que la idea es precisamente identificar los motivos y la sexualidad animal del dueño y del caballo.

Éste es quizás el exemplum breve más logrado del libro, el cual al parecer dejó tan impresionado al Arcipreste de Talavera que lo remodeló con un sujeto humano en su sátira sobre el amante cortés, consumido por la vanidad del loco amor. Gerli, en la introducción a su edición del Corbacho, alaba esta escena como "una pequeña obra maestra en que resalta el agudo poder observador del predicador medieval. En él se hace patente la frivolidad, presunción y vanidad del loco amor"' (Alfonso Martínez DE Toledo, Arcipreste de Talavera, o Corbacho, ed. de M. Gerli, Cátedra, Madrid, 1979, p. 35). Sin embargo, si comparamos ambos pasajes, podemos observar que la escena debe por lo menos tanto a Juan Ruiz como a la vida real, incluso hasta en el detalle de la aparición del asno: "quando toma su cavallo... quando fuere por la calle non guardara asnos ni burros, pobres nin mal vestidos, que con todos non tope muy descortesmente, sin manzilla nin duelo, con la fantasia e orgullo que en el celebro lieva de su dama; muy estirado sobre su silla..." (ibid., p. 127).

18 "Apuntes para un comentario literal del Libro de buen amor", BRAE, 43 (1963), p. 320.

19 Véase Emilio Braidotti, Eroticism in the "Libro de buen amor", tesis doctoral inédita, University of Pennsylvania, 1981, p. 180.

${ }^{20}$ Gf. valens, valentulus "vir aut mulier corporis solidi ei sueco pleni, ui necesse estad officum veneris", en P. PierRugues, Glossarium Eroticum Linguae Latinae, Herman Barsdorf Verlag, Berlin, 1908, p. 501.

${ }^{21}$ Véase D. G. Clarke, "Juan Ruiz and Andreas Capellanus", $H R, 40$ (1972), 390-411; véanse también las frecuentes imágenes que comparan a la gente pecadora con los animales en el Corbacho (C. NePAulsingh, "Talavera's imagery and the structure of the Corbacho", RCEH, 4, 1979-80, 339-340).

22 Véase el excelente estudio de D. Devoto, "El mal cazador", HDA, p. 490 que, siguiendo a Jung, cita un ejemplo de García Lorca en Yerma: "pi- 
Muy pocos versos y tan sólo un exemplum (que ilustraría mejor la ingratitud) están dedicados al tercer vicio, la avaricia. Esto se debe probablemente a que Juan Ruiz no logra distinguirla claramente de la codicia, con la cual aparece unida en muchas listas medievales. Ya hemos visto que el último de los cuentos ilustrativos sobre la codicia trataba de la avaricia.

A pesar de haber declarado que la codicia es la raíz de todos los pecados, Juan Ruiz dedicará a la lujuria, el cuarto pecado, la máxima atención y el mayor número de ejemplos ilustrativos. Esto tiene sentido si recordamos que al principio había acusado abiertamente de ser la causa de todos los pecados a Don Amor, quien representa el amor sensual. Sin embargo, existe un conflicto entre esta acusación y el tema del libro, por una parte, y, por otra, la tradición que cataloga a la codicia como el primero de los pecados. Juan Ruiz parece resolver este conflicto felizmente, haciendo que ambas sean prácticamente sinónimas en su descripción. La acusación del Arcipreste a Don Amor y la definición de lujuria recuerdan la natura del hombre, diferenciada de la de otros animales por desear la unión sexual a cualquier hora y con cualquier mujer:

257a-c Siemprë está loxuria adoquier que tú seas, adulterio e fornicio todavía deseas: luego quieres pecar con qualquier que tú veas ${ }^{23}$.

En el pecado de lujuria es donde aparece el exemplum más extremado, el de Virgilio, quien en la Edad Media tenía fama de mago ${ }^{24}$. Sintiéndose engañado por una mujer que ridiculiza sus

sas" dice la Vieja a Yerma, "y al fondo de la calle relincha el caballo". De tono muy similar es un pasaje de la Celestina: "¿Relincháis don cavallo? ¿No basta un celoso en casa?... ¿o barruntas a Melibea?", donde celoso es utilizado en el sentido de 'ardiente, vehemente en deseos, lujurioso'; cf. en este artículo la discusión del pecado de la envidia; véase también B. RowLAND (Animals with human faces, pp. 103-112), donde se habla del caballo como símbolo fálico en el folklore.

${ }^{23}$ En la penitencia de Don Carnal contra el pecado de lujuria hay otra advertencia muy parecida sobre la condición insaciable del hombre: "non guardeste a casadas nin a monjas profesas / por cumplir tu furnicio faziés grandes promessas"'(1166cd).

${ }^{24}$ Sobre la tradición de Virgilio en el medievo y su fama de mago, véase Domenico Comparetri, Vergil in the Middle Ages, 1908, reed., Archon Books, Hamden, 1966; y JoHn WeBSTER SPARgo, Virgil the necromancer, Harvard University Press, Cambridge, 1934. Existen varias leyendas que asocian a Virgilio con mujeres. La primera y más común presenta a Virgilio enamorado de 
intentonas sexuales, Virgilio se venga, dejando a toda Roma sin luz:

263 assí que los romanos, fasta la criatura, non podién aver fuego, por su desaventura, si non lö encendían dentrö en la natura de la mujer mesquina...

No sin razón añade Juan Ruiz que Virgilio jugó una mala pasada ("muy mal juego") a la desafortunada mujer. Sigue otro malévolo truco de Virgilio, el cual seca el río Tíber, convirtiéndolo en cobre, quizás queriendo representar con la sequedad del río la aridez afectiva de la dama.

Un buen ejemplo de la habilidad de Juan Ruiz para adaptar una pieza heredada sin relación aparente con su propósito central es el cuento siguiente, que ilustra la lujuria, en el que el águila, al ser atravesada por la flecha de un cazador, se da cuenta que la pluma en la cola de la flecha mortal es una de las suyas. El águila con sus plumas representaba generalmente la soberbia; la relación con la lujuria, que no es obvia, es señalada por Juan Ruiz por medio de una moraleja bastante retorcida: así como el águila se destruyó a sí misma, el amante se encamina hacia su autodestrucción tan pronto como "ha satisfecho su deseo lujurioso":

una hija del Emperador de Roma, la cual consiente dejarle entrar en su habitación, situada en una torre, haciéndolo subir en una caja; sin embargo, cuando está a medio camino, la mujer perversa lo deja colgando en el aire hasta la mañana siguiente para que todos lo vean y se burlen de él. El castigo que Virgilio impone a la mujer es exactamente como Juan Ruiz nos lo describe. Según CompareTti (pp. 326-332), la historia consta de dos partes distintas, el ultraje y la venganza. La primera pertenece a las historias tradicionales y misóginas de la Edad Media que ilustran que un hombre, por muy grande que sea, nunca está a salvo de las astucias y manejos de las mujeres. Personajes tales como David, Sansón, y Aristóteles han cedido sus nombres a estas historias, a veces intercambiándose entre sí.

La primera versión conocida de la segunda parte de la historia data de 1220. Como es obvio, las dos historias están unidas sin lógica, pues Virgilio, el mago de la segunda historia, no tiene tales poderes en la primera mitad, de lo contrario no hubiera necesitado verse en una situación tan vergonzosa. SPARGo (pp. 147-197) explica detalladamente por qué el estar suspendido de una cesta representaba una vergüenza tan horrible, motivando así la terrible venganza de Virgilio. Quedar suspendido de una cesta era uno de los castigos prescritos para los criminales por algunos códigos municipales medievales en Alemania y en otros países. Spargo habla también de la tradición de la venganza del mago por medio del fuego como una expiación de los pecados. Sin embargo, no se encuetran citados por ninguna parte antecedentes del segundo acto vengativo de Virgilio en el episodio del $L B A$, el secar el río Tiber. 
274 omnë, avë o bestia a quë amor retiente, desque cumple luxuria luego së arrepiente: entristecë en punto, luego flaqueza siente; acórtase la vida...

Se trata de una amplificación de la máxima post coitum tristis est, con el sintagma omne, ave, animalia que nos hace recordar una vez más "la natura del omne", y con una moraleja que repite la lección del "garçón que quería casar con tres mujeres", el cual después de un mes de matrimonio pierde todo su vigor físico. Mientras que bajo la natura del hombre Juan Ruiz señaló, como hemos visto, que hombres, pájaros y bestias desean inevitablemente el sexo (73b), la moraleja final de este exemplum subraya, con la repetición de un sintagma virtualmente idéntico, que "omne, ave o bestia" (274a) también se encaminan hacia la muerte y la condenación como resultado de sus excesos sexuales.

Finalmente, debemos observar que aunque otros comentaristas (por ejemplo, Chaucer o López de Ayala) tradicionalmente califican como particularmente reprensibles al incesto y a la homosexualidad debido a su condición "contra-natura", Juan Ruiz no parece tener interés en las discusiones teológicas sobre la desviación sexual y prefiere explayarse en la lujuria común. Incluso cuando se menciona a las religiosas, no es para destacar específicamente el grave pecado que supone seducir a monjas sino para subrayar una vez más que la condición del hombre es desear a todas las mujeres, sean estas "casadas", "esposas", "vírgenes", o "religiosas" (231cd).

En el quinto pecado aparece otra indecisión terminológica cuando Juan Ruiz identifica la envidia con los celos y también hasta cierto punto con la ira (el pecado que aparecerá en quinto lugar en la penitencia de Don Carnal). Los tres vocablos no se utilizan en su sentido general, sino de acuerdo con su significado más restringido en la terminología del amor cortés. La envidia, en su sentido más general de "mirar con descontento la posesión más ventajosa de otro", no está ejemplificada. El término parece utilizado como sinónimo del término provenzal medieval enveja 'concupiscencia, deseo' 25 y queda asociado exclusivamente con celos, que tampoco se utiliza en su sentido generalizado posterior de 'sospecha, desconfianza', sino tan sólo como celos sexuales. Celos se deriva en última instancia de zelosus, un calco bíblico de

${ }^{25}$ GLYNN CROPP, Le vocabulaire courtois des troubadours de l'époque classique, Doz, Genève, 1975, pp. 270-271. 
una palabra hebrea que significa 'ardiente, fogoso'. Aparece por primera vez en el siglo XII con un sentido secularizado en provenzal antiguo gelos, gilos 'celoso enamorado', aplicado solamente a los hombres y en particular al esposo celoso ${ }^{26}$.

Compárese también jealous en inglés medieval 'resentido frente a otro por causa de una rivalidad conocida o sospechada'; 'tener un amor que no tolera la infidelidad por parte del objeto amado' (Oxford Universal Dictionary). En la poesía trovadoresca provenzal ira es un término ambiguo pero utilizado con muchísima frecuencia para caracterizar el sufrimiento del amante. Puede significar 'ira' y, con mayor frecuencia, 'tristeza'; quizás sea, más concretamente, una emoción compleja en la que se confunden la tristeza y la ira ${ }^{27}$. Así se explica por qué en el $L B A$ los celos hacen que el amante sospechoso en extremo busque reyertas:

277a-c El celo siempre nace de tü embidia pura, teniendo que a tu amiga otro l'fabla en locura; por esto eres celoso, e triste con rencura.

Al mismo tiempo se dice que los celos tienen el efecto opuesto y hacen que el corazón del amante lata más rápidamente, para que se sienta débil y pierda su vigor. Por último, de igual manera que los efectos de la lujuria, citados anteriormente, los celos llevan al amante a la destrucción final. Paradójicamente, mientras que aquí el Arcipreste acusa a Don Amor de ser la causa de los celos del amante, Amor, en su respuesta "razonada", le aconsejará evitar los celos insensatos para tener éxito en el amor o para conservarlo:

$558 \mathrm{a}-\mathrm{c}$ non seas maldeziente nin seas embidioso. A la mujer que es cuerda non le seas celoso: sï algo no l'provares no l'seas despechoso.

Amor hace una burla parecida en sus castigos, diciéndole al Arcipreste que debería dar, o al menos prometer, regalos porque las mujeres harían cualquier cosa por dinero: "La mujer cobdiciosa... / por joyas e dineros salirá de carrera" ( $51 \mathrm{lbc}$ ). El consejo de Amor es una repetición verbal de la acusación que el Arcipreste había incluido en la codicia con respecto a los hombres que ro-

${ }^{26}$ Leo SPITZer, reseña de M. GRzYwaCz, "Eifersucht"' in den romanischen Sprachen, Ro, 64 (1913), 264-303; CROPP, op. cit., pp. 246-249.

${ }^{27}$ Ibid., pp. 287-290. 
ban a los caminantes joyas y dinero para poder cumplir con los regalos prometidos a sus amantes. En suma, nos encontramos con un ridículo debate circular, en el cual después de que Amor es acusado de causar varios pecados, la mejor contestación que ofrece es, por una parte, aconsejar que el amante cometa esos mismos pecados para tener éxito en el amor o, todavía con menos lógica, ¡que los evite a pesar de que él, quien pronuncia este consejo, es la misma causa de ellos!

La fábula que ilustra la envidia trata de la corneja tan celosa de las hermosas plumas del pavón que:

$$
\begin{aligned}
& 286 \text { peló todo su cuerpo, su cara é su ceja, } \\
& \text { de péndolas de pavo vistió nueva pelleja; } \\
& \text { fermosa, e non de suyo, fuése para la igreja. } \\
& \text { Algunas fazen esto que fizo la corneja. }
\end{aligned}
$$

Es decir, la corneja es como esas mujeres que se maquillan para ir a la iglesia, adonde no van por piadosas sino por coquetas. Los autores medievales se servían de la figura de la corneja en los exempla para ilustrar varios pecados, con dos cuentos particularmente comunes que se utilizaban en contra de las mujeres. La fábula de la corneja blanca que Apolo convierte en negra como castigo por haber chismeado sobre la infidelidad de su esposa mostraba que las mujeres no pueden callarse. El cuento de la corneja que se viste con las plumas del pavón pero que no puede engañar a éste con su plumaje prestado se utilizaba para criticar a las mujeres que usaban cosméticos y pelucas ${ }^{28}$. Juan Ruiz, al usar la segunda historia, también incorpora elementos de la primera, pues el castigo de la corneja es que el pavón la echa a un estercolero, con lo cual sale más negra... que el erizo ${ }^{29}$.

El tema de la iglesia como lugar para encuentros sexuales reaparece en las "Horas canónicas", en donde el cura hipócrita y falsamente pío utiliza la iglesia para encontrarse con feligresas sumisas; también se encuentra en el episodio en donde el protagonista va a la iglesia con el fin de poder ver a la dueña en oración

28 Rowland, Birds with human souls, pp. 35-36.

29 En el verso "más negra parecía la graja que el erizo" (288d), la cor neja es llamada graja. Aparentemente, la confusión entre varios miembros de la familia de la corneja, como la misma corneja, la graja y la chova, parece haber sido muy corriente (Rowland, Animals with human faces, p. 87). Compárese con esta fábula el refrán todavía corriente en italiano: farsi bello con le penne del pavonne (Carla Pekelis, $A$ dictionary of colorful Italian idioms, George Braziller, New York, 1965). 
(1322), e inmediatamente después, cuando logra ver a la monja Garoza en la iglesia y dice con palabras sacrílegas: "En el nombre de Dios fui a missa de mañana, / vï estar a la monja en oración..." (1499ab).

El sexto pecado, la glotonería, comienza con un juego de palabras equívoco en su misma definición. En el primer verso se acusa a Don Amor de ser un glotón, pero en el segundo ya se hace patente la golosina especial que está buscando: 291 bc querriés a quantas vees gostarlas tú primero;
enflaqueces, pecado, e eres grand venternero

Es decir, "cada mujer que ves, desearías ser el primero en gustarla". Después se muestra que la glotonería lleva al otro pecado carnal, la lujuria, y finalmente a la muerte repentina sin confesión y, por lo tanto, a la condenación:

293a-c Con la mucha vianda e vino crez la flema; duermes con tü amiga, afógate postema, liévatë el diablo, en infierno te quema.

La asociación de la lascivia con la muerte sin arrepentimiento es muy común en todo el medioevo ${ }^{31}$. Juan Ruiz añade también que fue el vino el que hizo a Lot "fazer fornicio" con sus hijas, y concluye con la moraleja:

$$
\begin{aligned}
& 296 \mathrm{~cd} \ldots \ldots \ldots \ldots \text {........ do mucho vino es, } \\
& \text { luegö es la loxuria e todo mal después. } \\
& \text { 297a Muerte muy rebatada trae la golosina. }
\end{aligned}
$$

El exemplum del ermitaño narrado por Don Amor en su res-

${ }^{30}$ Compárese la aparición del término venternero 'glotón' en 'Las ranas que querían un rey", en la caracterización de la cigüeña glotona, que también representa claramente a Amor: 202cd "andando picoabierta; como era venternera / de dos en dos las ranas comía bien ligera".

${ }^{31}$ Compárese, por ejemplo, el cuento del speculum Laicorum, que ilustra el pecado de la lascivia, en donde el protagonista, después de una noche de exceso sexual, "murió de repente sin arrepentirse" (citado en KAHRL, art. cit.). La asociación de la glotonería con la lujuria tiene una larga tradición. Véase MikHail BaKHTIN, Rebelais and his world, tr. by H. Iswolsky, MIT Press, Cambridge, 1968, p. 294, quien dice que en la literatura popular en latín de los siglos XII y XIII ambas imágenes de banquetes y fuerzas procreadoras son ilustradas por la figura de un monje, el cual puede representar negativamente la glotonería y la embriaguez pero también representa las fuerzas positivas carnavalescas de la procreación y el regocijo. 
puesta al Arcipreste podría incluirse aquí. El diablo tienta al ermitaño, diciéndole que el vino es la sangre de Cristo y que "en ello yaze / sacramento muy santo"' (534bc). El ermitaño se emborracha y acaba violando y matando a una mujer. La moraleja vuelve al tema de la codicia, entendida en sentido estricto de "lujuria"':

540 Fue con ël la cobdicia raíz de todos males: luxuria ë sobervia; tres pecados mortales; luegö el omicidio: estos pecados tales trayë el vino mucho a los descumunales.

Es curioso el último cuento sobre la glotonería, acerca del león y el caballo, porque ambos animales cometen el mismo pecado y ambos son castigados fatalmente. Mientras la historia en sí está relacionada tan sólo con la simple glotonería, su moraleja vuelve repetidamente al tema de los pecados carnales que llevan a la muerte:
303a-c El comer sin mensura e la grand venternía, otrossí mucho vino con mucha beverría, más mata que cuchillo...

El séptimo pecado, la ira, confundida con la vanagloria, se trata con brevedad, mencionando de pasada a Nabucodonosor, Sansón y Saúl, y con una sola fábula totalmente desarrollada, la del león que se suicida a causa de su ira. La fábula trata solamente la ira en un sentido general y no contiene referencias sexuales obvias, probablemente debido a que su tratamiento aquí resulta redundante, por haber sido mencionada con anterioridad en el capítulo de la envidia, en forma de celos sexuales que incitan al amante a la ira y a buscar peleas. Sin embargo, la sección introductoria del pasaje, que se centra en la vanagloria, se utiliza (al igual que la envidia, los celos y la ira, en el quinto pecado) con su connotación de amor cortés, 'altanería, arrogancia, desdén, complacencia y vanidad', lo opuesto a la mezura, el ideal del amante cortés $^{32}$. El ímpetu y la fogosidad (brío) parecen acompañar a la vanagloria, en relación muy directa con la sexualidad, puesto que los vanagloriosos son acusados de pregonar sus éxitos amorosos, o garçonerías (307b), lo que los lleva a pelear e incluso a cometer homicidios. 
El último pecado, la acidia o pereza, es la negligencia en el cumplimiento de obligaciones religiosas o acciones piadosas, a menudo una peligrosa tentación para los clérigos. Juan Ruiz considera que la pereza va acompañada por la hipocresía, que, más correctamente considerada, es su resultado. Ambas se definen conjuntamente en términos sexuales: "pensandö estás triste, tú ojo non se erzía; / do vees la fermosa oteas con raposía" (319cd). Es decir, "eres demasiado indolente hasta para alzar los ojos, pero tan pronto como alcanzas a ver una mujer hermosa, la acechas como a una presa"'. Deberíamos recordar que mientras que el amor cristiano entra por medio de la razón, se dice que la lujuria, que empieza de una manera insinuante, se desarrolla ex visione, por medio de flechazos de amor ${ }^{33}$. Este pecado va acompañado por los dos exempla más extensos del libro. El primero, una amplificación de la fábula esópica Lupus et vulpis, judice simio, es una burla de los tribunales de justicia, las discusiones forenses y la hipocresía en genera ${ }^{34}$. Aunque este cuento sirve principalmente para ilustrar la hipocresía del lobo (322a "lo qué el más fazía a ötros lo acusava", con la misma idea enfatizada en los versos paralelos de $322 \mathrm{bcd}$ ), éste es acusado de cometer también los dos pecados carnales correlacionados, glotonería y lujuria. Tanto la hipocresía del lobo como sus robos están motivados por sus celos y su glotonería. Cuando al principio del cuento ve a la zorra robar una gallina y la acusa del delito, lo hace porque no puede soportar el contemplar con envidia como ella come lo que él tanto codiciaba: 321d "Él non veyé la ora que estoviese en tragallo". Después, el abogado defensor de la raposa, el perro pastor, intenta desacreditar el testimonio del lobo con un doble ataque a su reputación: primero, por su glotonería, por ser un ladrón que ha matado ovejas muchas veces para satisfacer su insaciable apetito (333d "ca él es fino ladrón c non falla qué le harte") y, segundo, por haber sido excomulgado debido a su vida adúltera con una "barragana pública" (337c) mientras mantenía a su esposa vi-

${ }^{33}$ Cf. el nombre del personaje alegórico Douze Regarz en el Roman de la Rose, Howard, op. cit., pp. 44-45; y ROBERTSON, op. cit., p. 49.

${ }^{34} \mathrm{El}$ único estudio detallado de este episodio es el de S. D. KIRBY, "Juan Ruiz and Don Ximio: The Archpriest's art of declamation", BHS, 55 (1978), 283-287, quien lo considera "fundamentally a showing off the poet's formidable knowledge both of law and rhetoric". Kirby no quiere aceptar ninguna intención paródica del episodio, lo que le hace desestimar la importancia del tema central, que es la hipocresía. Véase también H. W. JAnson, Apes and ape lore in the Middle Ages and the Renaissance, The Warburg Institute, London, 1952, p. 39. 
viendo en la penuria. La conclusión de la fábula, a la vez que sirve para introducir el segundo exemplum del mismo pecado, caracteriza a Amor como un diablo hipócrita que enreda a sus víctimas con engaños, y siempre las prefiere jóvenes y con buena salud $(372-73)$.

El segundo exemplum de acidia es el de las "Horas canónicas", quizás el episodio más obsceno del libro, al mismo tiempo que un perfecto ejemplo de la pereza, la hipocresía y la lujuria de los clérigos. También es una parodia de la alborada erótica y de las horas canónicas, pues ir a misa sirve al cura como excusa para encontrar mujeres sumisas:

380ac Tú vas luegö a la iglesia... más que por oír la missa quieres la missa de novios

nin ganar de Dios perdón: sin gloria ë sin razón.

Los solemnes versos latinos de las horas sirven para describir escenas de un encuentro amoroso. Juan Ruiz concluye de manera chocante con versos sacados de las completas, lo que resulta particularmente sacrílego, pues el segundo verso de este himno litúrgico es una oración de castidad nocturna ${ }^{35}$. En la subversión de Juan Ruiz el himno termina:

386a-c Nunca vi curas dë almas que tan bien diga completas: vengan fermosas o feas, o quier blancas o quier prietas, dígante: "Cionvertenos», de gradö abres las puertas.

Pocas dudas quedan sobre el significado de la imagen "puertas", si la comparamos con su posterior aparición aforística en el consejo de Don Amor al Arcipreste sobre como obtener favores sexuales ${ }^{36}$ :

${ }^{35}$ Los versos latinos rezan: Procul recedant somnia / Et noctium phantasmata / Hostem que nostrum comprime / Ne polluantur corpora. Se pueden ver paralelismos muy interesantes con el "Reeve's tale" de Chaucer, el cual es también una parodia doble de las completas y de las albas. Véase R. B. Kaske, "An Aube in the Reeve's tale", ELH, 26 (1959), 295-310; R. M. Correale, "Chaucer's parody of compline in the Reeve's tale", Chaucer Review, 1 (196667), $161-166$.

${ }^{36}$ Compárese también el double entendre en la queja del protagonista después de la muerte de Trotaconventos: $1519 \mathrm{~cd}$ "...que mucha buena puerta / me fue después cerrada que ante me era abierta". Compárese también La Lozana andaluza: "abrilde vos la puerta...ese hurón no sabe cazar en esta floresta", donde puerta 'pudenda', hurón 'pene' (cf. LBA, 1619c, 1623a) para hurón, véase mi artículo "La semiología de la connotación: lectura polisémica de "Cruz cruzada panadera"”, NRFH, 32 (1983), 299-324. Véase también el verso fi- 
$573 a-c$ Si tú guardar sopieres esto que te castigo eras te dará la puerta quien te oy cierra el postigo; la que të oy desama quererte ha eras amigo.

El tema que satura la digresión sobre los pecados capitales, en completa armonía con la obra en su totalidad, representa el gran debate del pensamiento cristiano medieval: la lucha eterna entre cupiditas, que conduce al pecado, a la muerte y a la condenación final, y caritas, que lleva a la salvación. En la digresión se subraya la cupiditas en su sentido estricto, como concupiscencia carnal, con insistencia particular en la natura del hombre, siempre insatisfecho, que desea a cualquier mujer, y por lo tanto se deja llevar a la destrucción física y espiritual. La originalidad de Juan Ruiz no reside tanto en declarar explícitamente que el amor sexual es causa de otros pecados como en mostrarlo implícitamente en la estructura de su obra, prestando una atención desproporcionada al pecado de la lujuria y asociándolo a los otros pecados. El Arcipreste de Talavera, por ejemplo, seguirá a Juan Ruiz al declarar que "el amor desordenado raíz es de todos lơs pecados mortales". Sin embargo, en su presentación de cada pecado, se extiende más en atención a la descripción de la avaricia y de varios otros pecados que en la de la lujuria. En el catálogo de pecados de Juan Ruiz, por otra parte, "todos los caminos conducen de nuevo a la lujuria'. Además, mientras la parte introductoria del $L B A$ es una sermón culto paródico, el cual con su thema sienta un principio estructurador general para la obra entera, con reapariciones constantes de los mismos grupos de palabras e ideas, la digresión sobre los pecados mortales es un sermón popular paródico que, mediante una divisio extra en forma de numerosos exempla, repite estos mismos temas ${ }^{37}$. Sigue al sermón temático reco-

nal muy sugestivo del romance Mora Moraima ( El romance viejo y tradicional, ed. M. Alvar, Porrúa, México, 1971, p. 126): "si no me abres tú, mi vida, aquí me verás matar. / Cuando esto oí, cuitada, comencé a levantar, / Vistiérame una almejía, no hallando mi brial, / Fuérame para la puerta, y abríla de par en par', donde la conclusión trunca sugiere que lo que va a seguir es un encuentro sexual violento. WhinNom (art. cit., p. 337) ofrece documentación adicional. A fin de que el lector no crea que lo sobredicho es mera especulación, compárese ese testimonio patentemente obsceno y poco poético (ROBERT Lehmann-Nitsche [seudónimo en la $1^{a}$ ed., VíCTOR BORDE], Los textos eróticos del Río de la Plata, $1^{\text {a }}$ ed. en alemán 1923; $2^{\text {a }}$ ed., en español, Librería Clásica, Buenos Aires, 1981): 193 “ ¿En qué se parece un coche a las bolas? En que se para en la puerta". 25 "La mujer del herrero / se cayó muerta / con la llave en la mano / y la puerta abierta".

37 Cf. A. C. Spearing ("The art of preaching and Pears plowman", en Cri- 
mendado por las artes praedicandi, pues no es meramente una digresión ornamental (en el sentido del ars poetica), sino que también se vale del concepto de utilitas, volviendo constantemente al thema central. Debemos recordar que los sermones medievales exageraban la mezcla de estilos, que para la mente medieval no resultaba incongruente tomar en serio una lección moral predicada a través de ejemplos paródicos e incluso obscenos, y que estos sermones estaban normalmente ejemplificados por medio de fábulas y cuentos ilustrativos ${ }^{38}$. Por ejempplo, Guibert de Nogent al principio del siglo XII, en su Liber que ordine sermo fieri debeat, señala a los predicadores que, al dar un sermón, a veces se consigue más discutiendo la naturaleza de los vicios que la de las virtudes:

La amonestación del predicador debería tratar tanto sobre el control y la manera de evitar el vicio como sobre el desarrollo y la protección de la virtud. Como maestro, que enseñe clara y seriamente qué pecados son "naturales» y cuáles son "contranatura», qué pecados son consecuencia de otros y lo pernicioso que son todos ellos en sí y en lo que ocasionan. Que muestre el fruto de cada pecado con detalle. He dicho claramente y he dicho a menudo que a veces se consigue más discutiendo la naturaleza de los vicios que discutiendo la naturaleza de las virtudes ${ }^{39}$.

Como ha demostrado Nepaulsingh ${ }^{40}$, la constante yuxtaposición de contrarios, o forma zigzagueante, crea un principio estructurador repetido a través de la obra. Empezando por el prólogo, cuyo propósito es "dar un aire de desorden indeciso a la obra en su totalidad", la ambigüedad persiste hasta la conclusión.

ticism and Medieval poetry, Barnes \& Noble, New York, 1965; reimpr., London, 1972, pp. 107-134, especialmente pp. 115, 124), quien al hablar de la obra de Langland señala que un sermón temático le presta unidad a la dipositio de la obra, "becoming a method of organization by which a sermon $[. .$.$] becomes$ an independent meditation closely and constantly related to a single thema $[\ldots]$ with frequent reappearances of the same sets of words and ideas"'. Spearing también apunta la analogía con las formas musicales complejas (analogía ya hecha en el siglo xIv) con una estructura basada en la recurrencia, la variación, la transposición y la recreación de cierto material temático fundamental.

${ }^{38}$ Lida De Malkield, ed., op. cit., p. 303; y Erich Auerbach, "The world in Pantagruel's mouth", en Mimesis, 3rd ed., Princeton University Press, Princeton, 1973, pp. 262-284.

39 Joseph Miller, H. Prosser, Thomas W. Benson, eds., Reading in Medieval rhetoric, Indiana University Press, Bloomington, 1973, p. 172. (La traducción es mía.)

40 "Sobre Juan Ruiz y las dueñas chicas", $C u H, 1975$, núm. 297, p. 649. 
Más que simple ambigüedad quizás podríamos describirla como una técnica de bluff, que incluye la ambigüedad al igual que la paradoja, el enigma, la disputa y la antítesis, utilizados no tanto para engañar al oyente como para hacerle pensar ${ }^{41}$. En la digresión sobre los pecados mortales se produce constantemente una yuxtaposición entre el amor físico como una satisfacción corporal momentánea, y la destrucción del cuerpo, la muerte y la condenación eterna, a la cual lleva inevitablemente. Recordemos, por ejemplo, las yuxtaposiciones particularmente violentas en los pasajes del caballo soberbio que ha de pagar, con las heridas que recibe en la batalla, los excesos sexuales de su dueño; del águila cuya muerte es ocasionada por una flecha que lleva sus propias plumas; del amante celoso que se destruye a sí mismo y a los demás; del borracho glotón que muere de un ataque en medio del acto sexual, y del fanfarrón sexual y vanaglorioso que se mete en reyertas y puede acabar cometiendo un homicidio. Juan Ruiz ha seguido indudablemente el consejo a los predicadores de hablar más sobre los vicios que sobre las virtudes y mostrar el carácter mortal y pernicioso de aquéllos. Sin embargo, cualquiera que sea la intención final de esta larga digresión, no se puede reducir sencillamente a un "cuadro horrible" de los males del pecado, ni a una "larga diatriba en contra del amor en base a principios cristianos", como han querido señalar algunos críticos ${ }^{42}$. Como apuntó acertadamente Zahareas ${ }^{43}$, la diatriba verbal del protagonista en contra de Don Amor tiene dos voces diferentes que se alternan, la voz firme de la superioridad moral sobre la degeneración pecaminosa y la voz quejumbrosa y aterrorizada del aprendiz frustrado en el amor que condena a Don Amor por haberlo engañado. Toda la invectiva y el catálogo de insultos contra Don Amor parecen ser una exageración humorística que resulta en la suma ridiculez del volte face final en donde los insultos del protagonista se detienen de repente con: "Mucho más te diría, salvo que non me atrevo" (421d). Este final es una parodia del topos de falsa modestia, pues el que el poeta sea incapaz de continuar no se debe

${ }^{41}$ Sobre el bluff en Rabelais, véase Barbara Bowen, The age of bluff: Paradox and ambiguity in Rabelais and Montaigne, University of Illinois Press, Chicago, 1972 .

42 Para la primera cita véase LeCoy, op. cit., pp. 178 ss.; la segunda es la opinión de G. B. GybBon-Monypenny, "The two versions of the Libro de buen amor', BHS, 39 (1961), p. 221.

${ }^{43}$ The art of Juan Ruiz, pp. 117-118 y "Structure and ideology in the Libro de buen amor', p. 96. 
a que el tema sea inexpresable sino al temor de que si prosigue, Amor no le ayudará en sus empresas.

Finalmente, se hace muy evidente la falta de lógica, cómica y retorcida, de todo el episodio con la respuesta "mesurada" de Don Amor, en el cual aconseja al poeta que para lograr éxito en el amor evite precisamente los mismos pecados y excesos de los cuales él mismo es la causa-raíz, según las acusaciones de su discípulo ${ }^{44}$. Por encima de todo, Amor aconseja en todas las acciones la mesura o la “moderación disciplinada por la razón", virtud que representa la misma esencia del amor cortés ${ }^{45}$ y lo opuesto a los excesos desmesurados, imprudentes e insensatos ocasionados por el mismo Amor. El grado de exsuperatio, al igual que la decidida falta de lógica del episodio entero, sugieren que en toda intención doctrinal, moralizante y seria quedaría subordinada para Juan Ruiz y su auditorio a la parodia festiva humorística dentro de la tradición medieval de irreverencia frente al ritual religioso diario. Tal irreverencia ha sido demostrada por la existencia, en los espectáculos públicos, carnavales y mercados, de diversiones paródicas de todos los ritos y ceremonias de la iglesia, tales como himnos paródicos, credos, liturgias, salmos, epitafios, al igual que de reglas monásticas, decretos y encíclicas eclesiásticas y, como hemos visto en el $L B A$, de sermones cultos y populares $^{46}$. Esta comicidad irreverente y constante era el resultado del poder y la tremenda importancia sociopolítica de la religión en la vida cotidiana de la sociedad medieval. El tradicional "mundo al revés" del carnaval ofrecía un escape temporal de la realidad de las prohibiciones religiosas y sociales, al igual que del miedo a lo sobrenatural y, finalmente, de la muerte.

LOUISE O. VASVARI

State University of New York at Stony Brook

44 Por ejemplo, Don Amor le aconseja al poeta que sea franco (573), lo opuesto de avariento; que no tome mucho vino (528-548), lo opuesto de ser glotón; que evite la altivez, la fanfarronería y la agresividad, es decir, la vanagloria y la ira.

45 CROPp, op. cit., pp. 421-425.

46 Sobre lo carnavalesco en la vida medieval, véase BAKHTin, op. cit.; so* bre la tradición irreverente del risus paschalis, véase FLUCK, art. cit. 